\title{
Computer-generated Conventional Key as a Tool of Commercial Evaluation of Some Mango Cultivars (Mangifera indica L.) in Saudi Arabia
}

\author{
Lamiaa F. Shalabi \\ Department of Biological and Geological Sciences, Faculty of \\ Education, Ain Shams University, Cairo, Egypt
}

\begin{abstract}
ACUMULATION of annual intra- and inter-cultivar variation in diagnostic attributes of the dioecious mango (Mangifera indica) fruit trees render the accurate identification of such cultivars beset with problems and uncertainty. To overcome these problems, a data matrix was compiled to incorporate comparative observations on 34 characters of the fruits of 14 cultivars of mango (Mangifera indica L.) collected from Jazan region, southwestern of Saudi Arabia. The set of characters was analyzed under the key-generating patch of computer programs DELTA. Detailed and item descriptions of all characters of each cultivar as produced by the programs are provided. The key serves the purpose of accurate identification of the cultivars and the detailed descriptions provide an easy means of confirming the identification. The inherent flexibility of key-generating computer programs allows for the periodic revision and updating of the key and the descriptions of cultivars as well as its expansion to accommodate additional taxa and/or characters. Correct identification of a cultivar is of vital economic importance because it is the most essential element in determining its market value and, consequently, its profitability.
\end{abstract}

Keywords: DELTA, Economic value, Identification, Intkey, Key, Mangifera indica, Mango

Mango (Mangifera indica L.: Anacardiaceae) is one of the world's most important tropical fruits, and is widely regarded as the most popular fruit in tropical and subtropical regions. Unlike the mango's long history in India, Pakistan and Brazil, mangos are not indigenous to Saudi Arabia. It was introduced only 30 years ago, but is popular among Saudis. Some mango trees in the region are reportedly over 100 years old. (Dawah et al., 2013). Farmers in Jazan, southwestern of Saudi Arabia begin to harvest thousands of tons of mango fruit in March. There has been a marked increase in the number of mango trees in the region and many more farmers are focusing on growing mangoes and other types of fruit. The region holds an annual mango festival to market this important produce inside and outside the Kingdom.

Mango fruit of the different cultivars varies in shape, size, appearance and internal characteristics. The fruit is a fleshly drupe, varying in size from 2.5-30 $\mathrm{cm}$ long, may be kidney-shaped, ovate or round and weigh from approximately $200 \mathrm{~g}$ to over $2000 \mathrm{~g}$. The leathery skin is waxy and smooth and when ripe

* Flora_Lamiaa@yahoo.com. 
entirely become pale green or yellow marked with red, depending on the cultivar (Griesbach, 2003).

Mangoes in general have good flavor, taste, aroma and texture and most varieties are consumed fresh. The perishable nature of mangoes and its short harvest season severely limits its use for fresh consumption and exportation (Marin et al., 1992). The desirable characteristics found in mango fruits are regular bearing, good fruit shape and flesh quality, weight of 300-400 g per fruit, extended production period and extended storage and shelf life, pest and disease resistance (Iyer and Dinesh, 1997).

Different local names for the same cultivar make characterization of germplasm important for better use of all genetic resources available. The International Plant Genetic Resources Institute (IPGRI) has developed a descriptor list to assist in the identification of cultivars. The list contains passport data for identifying the accession and information recorded by collectors (IPGRI, 2006).

Morphological characterization is traditionally the most common method used for studying many different crops (González et al., 2002) such as mango (Ascenso et al., 1981; Illoh and Olorode, 1991; Jintanawong et al., 1992; Subedi et al., 2009 and Mussane, 2010). However, the mango trees are dioecious and there is no guarantee that pollination of a tree with female flowers will always take place by pollen from the same tree with male flowers so that the morphological and other characteristics of the fruit will remain constant. Consequently, accumulation of annual variation in these characteristics reduces their value as means of identifying mango cultivars whose correct identity becomes shrouded with uncertainty. This highlights the urgent need for an easy and reliable method of periodic revision and updating of the key to the mango cultivars and the widely available key-generating computer programs seemed to provide the required method.

The general objective of this study was to identify and evaluate the main characteristics of 14 varieties of mango at Jazan region, southwestern of Saudi Arabia. The specific objectives were to discriminate the 14 mango varieties using morphological and morphometric characterization of fruits and seeds and make recommendations regarding the suitability of different varieties for fresh consumption, local consumption, exportation or fruit processing.

\section{Samples}

\section{Material and methods}

The present study is based on specimens of 14 cultivars of Mango (Mangifera indica) in Jazan. These well-identified specimens were collected from Jazan Agricultural Research Station at Abu Arish. Aspects of morphological and morphometric variation of fruits and seeds are recorded comparatively for the taxa into a data matrix (see Appendix). At least 10 specimens of each cultivar were used for recording its diagnostic attributes.

Egypt. J. Bot., Vol. 56, No. 3 (2016) 


\section{Data analysis}

The 34 morphological and morphometric characters defined in Table 1 were recorded comparatively for each of the 14 cultivars into a data matrix (See Appendix). Of these characters only eight are multistates while the remaining 26 are binary. The IPGRI descriptors for mangoes (2006) were used as a guide to put the character list (Table 1) to achieve maximum contrast between states of the same character, and be as easily observable as possible. For the extent of data collection, 10 fruits were used as established by the IPGRI method. The set of programs DELTA as described by Dallwitz et al. (2000) was used in key-generation as well as in the production of coded and detailed descriptions of the cultivars.

\section{Results}

Application of DELTA to the data matrix produced the following key to the 14 mango cultivars. The key is followed by additional results of the DELTA run in the form of detailed descriptions of character-states recorded for every cultivar in natural language (i.e. cultivars' descriptions) and in terms of the serial numbers assigned to them in Table 1 (i.e. coded descriptions).

Characters: 34 indata, 34 included, 12 in key.

Items: 14 in data, 14 included, 14 in key.

Parameters: Rbase $=1.40$ Abase $=2.00$ Reuse $=1.01$ Varywt $=.80$

Characters included: $1-34$

Character reliabilities: $1-34,5.0$

1 .

Fruit beak perceptible. ... 2

Fruit beak mammiform ......................... 4

Fruit beak pointed ….................................................................... 7

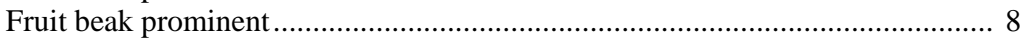

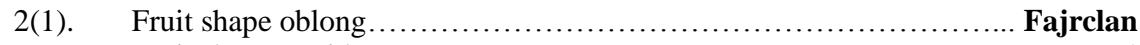

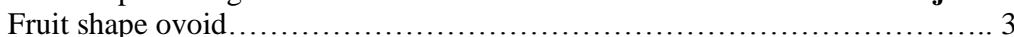

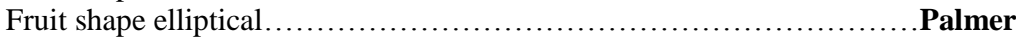

3(2). Fruit apex roundish; pulp of ripe fruit very juicy; fruit diameter 7-9 cm; fruit colour yellow with red blush............................................eitt Fruit apex acute; pulp of ripe fruit slightly juicy; fruit diameter $9.5-11 \mathrm{~cm}$; fruit colour yellow................................................... Kensington

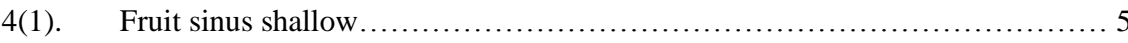

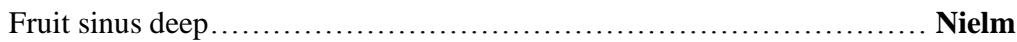

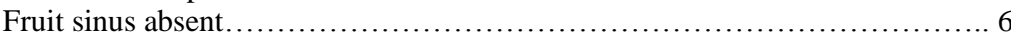

5(4). Fruit shape oblong; fruit colour yellow; fruit skin less than $2 \mathrm{~mm}$ thick; colour of ripe fruit pulp orange ..............................Kitchner(Sudani) Fruit shape ovoid; fruit colour yellow with red blush; fruit skin $2 \mathrm{~mm}$ thick or more; colour of ripe fruit pulp yellow.

Hedan

6(4). Fruit shape oblong; fruit diameter $9.5-11 \mathrm{~cm}$; fruit stalk cavity absent; texture of ripe fruit pulp firm ................................................................. Qalb al-thoor Fruit shape ovoid; fruit diameter 7-9 cm; fruit stalk cavity present; texture of ripe fruit pulp loose Tommy Atkins

7(1). Fruit sinus shallow; pulp of ripe fruit juicy ....................................... Van Dyke Fruit sinus deep; pulp of ripe fruit slightly juicy ...................................... Nagwa Fruit sinus absent; pulp of ripe fruit very juicy ........................................... Zill 
8(1). Fruit shape oblong; pulp of ripe fruit slightly juicy; fruit weight $300-450 \mathrm{gm}$; fruit apex obtuse Sensation Fruit shape ovoid; pulp of ripe fruit juicy; fruit weight 500-700 gm; fruit apex acute. Al-khad al-gameel

TABLE 1. List of 34 morphological and morphometric characters recorded comparatively for 14 Mango cultivars from Jazan, southwestern of Saudi Arabia and used in key generation.

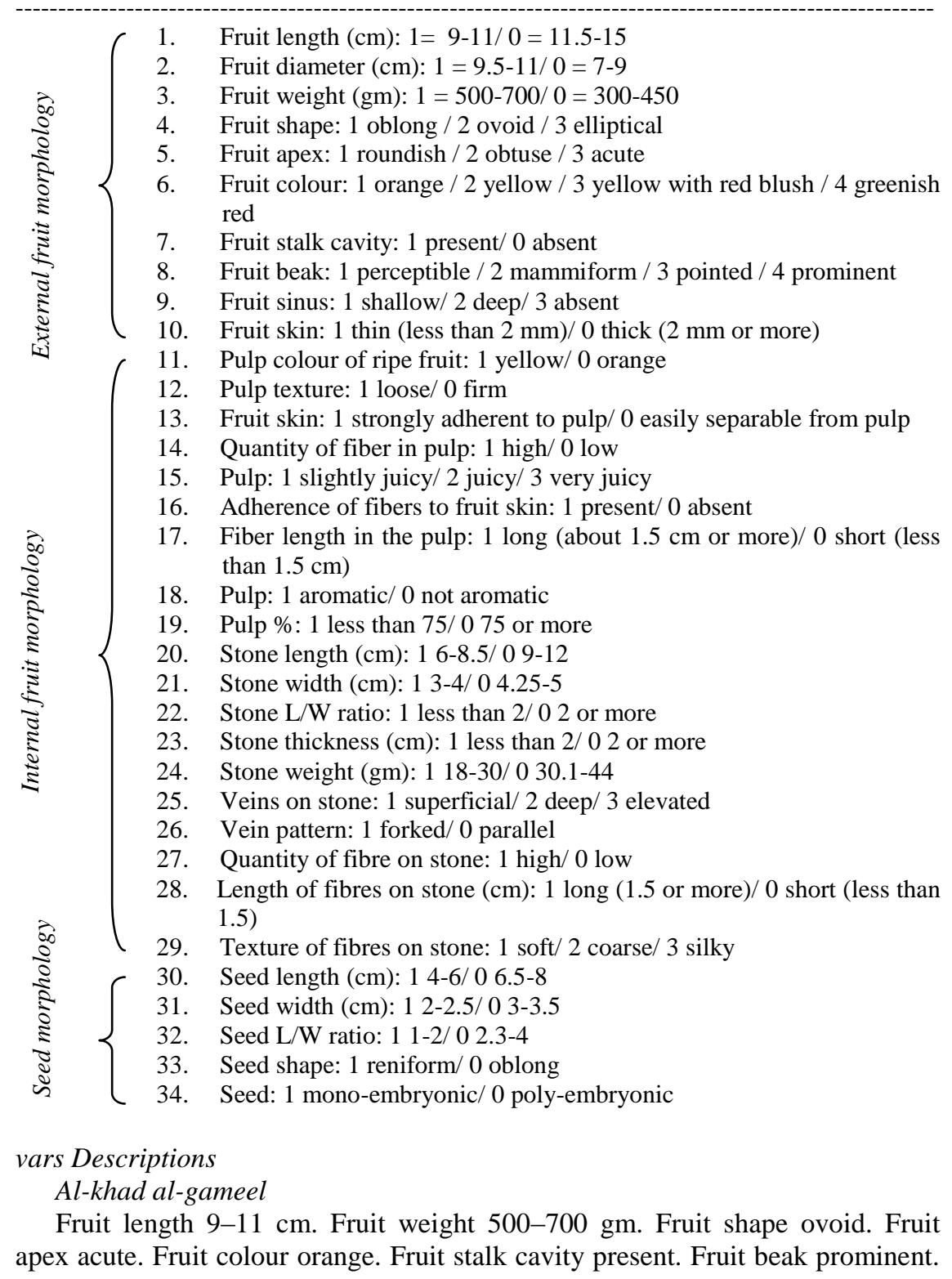

Egypt. J. Bot., Vol. 56, No. 3 (2016) 
Fruit sinus absent. Fruit skin $2 \mathrm{~mm}$ thick or more. Colour of ripe fruit pulp orange. Texture of ripe fruit pulp firm. Fruit skin strongly adherent to pulp. Quantity of fibre in pulp low. Pulp of ripe fruit juicy. Fibres not adherent to skin of ripe fruit. Length of fibres in pulp less than $1.5 \mathrm{~cm}$. Pulp of ripe fruit not aromatic. Pulp $75 \%$ or more. Stone length $6-8.5 \mathrm{~cm}$. Stone width $3-4 \mathrm{~cm}$. Stone length/width ratio less than 2 . Stone thickness less than $2 \mathrm{~cm}$. Stone weight $18-$ $30 \mathrm{gm}$. Veins on stone elevated. Quantity of fibres on stone high. Fibres on stone less than $1.5 \mathrm{~cm}$ long. Fibres on stone coarse. Seed length $4-6 \mathrm{~cm}$. Seed width 3 $-3.5 \mathrm{~cm}$. Seed length/width ratio $1-2$. Seed oblong. Seeds poly-embryonic.

\section{Fajrclan}

Fruit length $11.5-15 \mathrm{~cm}$. Fruit diameter 7-9 cm. Fruit weight 500-700 gm. Fruit shape oblong. Fruit apex roundish. Fruit colour yellow. Fruit stalk cavity present. Fruit beak perceptible. Fruit sinus shallow. Fruit skin $2 \mathrm{~mm}$ thick or more. Colour of ripe fruit pulp yellow. Texture of ripe fruit pulp firm. Fruit skin strongly adherent to pulp. Quantity of fibre in pulp low. Fibres adherent to skin of ripe fruit. Length of fibres in pulp less than $1.5 \mathrm{~cm}$. Pulp of ripe fruit aromatic. Pulp $75 \%$ or more. Stone length 9-12 cm. Stone width $4.25-5 \mathrm{~cm}$. Stone length/width ratio 2 or more. Stone thickness less than $2 \mathrm{~cm}$. Stone weight $30.1-44 \mathrm{gm}$. Veins on stone superficial. Quantity of fibres on stone high. Fibres on stone less than $1.5 \mathrm{~cm}$ long. Fibres on stone coarse. Seed length $6.5-8 \mathrm{~cm}$. Seed width $2-2.5 \mathrm{~cm}$. Seed length/width ratio $2.3-4$. Seed reniform. Seeds mono-embryonic.

\section{Hedan}

Fruit length $9-11 \mathrm{~cm}$. Fruit diameter 7-9 cm. Fruit weight $300-450 \mathrm{gm}$. Fruit shape ovoid. Fruit apex obtuse. Fruit colour yellow with red blush. Fruit stalk cavity absent. Fruit beak mammiform. Fruit sinus shallow. Fruit skin $2 \mathrm{~mm}$ thick or more. Colour of ripe fruit pulp yellow. Texture of ripe fruit pulp loose. Fruit skin strongly adherent to pulp. Quantity of fibre in pulp high. Pulp of ripe fruit very juicy. Fibres adherent to skin of ripe fruit. Length of fibres in pulp about $1.5 \mathrm{~cm}$ or more. Pulp of ripe fruit aromatic. Pulp less than $75 \%$. Stone length $6-8.5 \mathrm{~cm}$. Stone width $3-4 \mathrm{~cm}$. Stone length/width ratio 2 or more. Stone thickness $2 \mathrm{~cm}$ or more. Stone weight $18-30 \mathrm{gm}$. Veins on stone deep. Quantity of fibres on stone high. Fibres on stone $1.5 \mathrm{~cm}$ long or more. Fibres on stone soft. Seed length $4-6 \mathrm{~cm}$. Seed width $2-2.5 \mathrm{~cm}$. Seed length/ width ratio 2.3-4. Seed oblong. Seeds mono-embryonic.

\section{Keitt}

Fruit length $9-11 \mathrm{~cm}$. Fruit diameter 7-9 cm. Fruit weight 500-700 gm. Fruit shape ovoid. Fruit apex roundish. Fruit colour yellow with red blush. Fruit stalk cavity absent. Fruit beak perceptible. Fruit sinus absent. Fruit skin less than $2 \mathrm{~mm}$ thick. Colour of ripe fruit pulp orange. Texture of ripe fruit pulp loose. Fruit skin strongly adherent to pulp. Quantity of fibre in pulp low. Pulp of ripe fruit very juicy. Fibres adherent to skin of ripe fruit. Length of fibres in pulp about $1.5 \mathrm{~cm}$ or more. Pulp of ripe fruit aromatic. Pulp $75 \%$ or more. Stone length $6-8.5 \mathrm{~cm}$. Stone width $4.25-5 \mathrm{~cm}$. Stone length/width ratio less than 2 . 
Stone thickness $2 \mathrm{~cm}$ or more. Stone weight $18-30 \mathrm{gm}$. Veins on stone elevated. Quantity of fibres on stone high. Fibres on stone $1.5 \mathrm{~cm}$ long or more. Fibres on stone soft. Seed length $4-6 \mathrm{~cm}$. Seed width $2-2.5 \mathrm{~cm}$. Seed length/width ratio $1-2$. Seed oblong. Seeds mono-embryonic.

\section{Kensington}

Fruit length 9-11 cm. Fruit diameter $9.5-11 \mathrm{~cm}$. Fruit weight 500-700 gm. Fruit shape ovoid. Fruit apex acute. Fruit colour yellow. Fruit stalk cavity present. Fruit beak perceptible. Fruit sinus absent. Fruit skin less than $2 \mathrm{~mm}$ thick. Colour of ripe fruit pulp yellow. Texture of ripe fruit pulp firm. Fruit skin strongly adherent to pulp. Quantity of fibre in pulp high. Pulp of ripe fruit slightly juicy. Fibres adherent to skin of ripe fruit. Length of fibres in pulp less than $1.5 \mathrm{~cm}$. Pulp of ripe fruit aromatic. Pulp less than $75 \%$. Stone length $6-8.5 \mathrm{~cm}$. Stone width 3-4 cm. Stone length/width ratio less than 2 . Stone thickness $2 \mathrm{~cm}$ or more. Stone weight $18-30 \mathrm{gm}$. Veins on stone deep. Quantity of fibres on stone low. Fibres on stone $1.5 \mathrm{~cm}$ long or more. Fibres on stone soft. Seed length $4-6$ $\mathrm{cm}$. Seed width $2-2.5 \mathrm{~cm}$. Seed length/width ratio $2.3-4$. Seed reniform. Seeds poly-embryonic.

\section{Kitchner (Sudani)}

Fruit length $9-11 \mathrm{~cm}$. Fruit diameter 7-9 cm. Fruit weight 300-450 gm. Fruit shape oblong. Fruit apex obtuse. Fruit colour yellow. Fruit stalk cavity absent. Fruit beak mammiform. Fruit sinus shallow. Fruit skin less than $2 \mathrm{~mm}$ thick. Colour of ripe fruit pulp orange. Texture of ripe fruit pulp loose. Fruit skin strongly adherent to pulp. Quantity of fibre in pulp high. Pulp of ripe fruit very juicy. Fibres adherent to skin of ripe fruit. Length of fibres in pulp about $1.5 \mathrm{~cm}$ or more. Pulp of ripe fruit aromatic. Pulp less than $75 \%$. Stone length $6-8.5 \mathrm{~cm}$. Stone width 3-4 cm. Stone length/width ratio less than 2. Stone thickness $2 \mathrm{~cm}$ or more. Stone weight $30.1-44 \mathrm{gm}$. Veins on stone superficial. Quantity of fibres on stone high. Fibres on stone $1.5 \mathrm{~cm}$ long or more. Fibres on stone silky. Seed length $4-6 \mathrm{~cm}$. Seed width $2-2.5 \mathrm{~cm}$. Seed length/width ratio $1-2$. Seed reniform. Seeds poly-embryonic.

\section{Nagwa}

Fruit length $11.5-15 \mathrm{~cm}$. Fruit diameter 7-9 cm. Fruit weight 500-700 gm. Fruit shape oblong. Fruit apex roundish. Fruit colour yellow. Fruit stalk cavity present. Fruit beak pointed. Fruit sinus deep. Fruit skin $2 \mathrm{~mm}$ thick or more. Colour of ripe fruit pulp orange. Texture of ripe fruit pulp loose. Fruit skin strongly adherent to pulp. Quantity of fibre in pulp low. Pulp of ripe fruit slightly juicy. Fibres adherent to skin of ripe fruit. Length of fibres in pulp about $1.5 \mathrm{~cm}$ or more. Pulp of ripe fruit not aromatic. Pulp $75 \%$ or more. Stone length $9-12$ $\mathrm{cm}$. Stone width 3-4 cm. Stone length/width ratio 2 or more. Stone thickness less than $2 \mathrm{~cm}$. Stone weight $18-30 \mathrm{gm}$. Veins on stone elevated. Quantity of fibres on stone low. Fibres on stone less than $1.5 \mathrm{~cm}$ long. Fibres on stone soft. Seed length $4-6 \mathrm{~cm}$. Seed width $2-2.5 \mathrm{~cm}$. Seed length/width ratio $2.3-4$. Seed reniform. Seeds poly-embryonic. 


\section{Nielm}

Fruit length $11.5-15 \mathrm{~cm}$. Fruit diameter $9.5-11 \mathrm{~cm}$. Fruit weight 500-700gm. Fruit shape oblong. Fruit apex obtuse. Fruit colour yellow. Fruit stalk cavity present. Fruit beak mammiform. Fruit sinus deep. Fruit skin $2 \mathrm{~mm}$ thick or more. Colour of ripe fruit pulp orange. Texture of ripe fruit pulp loose. Fruit skin strongly adherent to pulp. Quantity of fibre in pulp high. Pulp of ripe fruit very juicy. Fibres adherent to skin of ripe fruit. Length of fibres in pulp about $1.5 \mathrm{~cm}$ or more. Pulp of ripe fruit aromatic. Pulp less than $75 \%$. Stone length $6-8.5 \mathrm{~cm}$. Stone width 3-4 cm. Stone length/width ratio 2 or more. Stone thickness $2 \mathrm{~cm}$ or more. Stone weight $30.1-44 \mathrm{gm}$. Veins on stone elevated. Quantity of fibres on stone low. Fibres on stone $1.5 \mathrm{~cm}$ long or more. Fibres on stone soft. Seed length $4-6 \mathrm{~cm}$. Seed width $2-2.5 \mathrm{~cm}$. Seed length/width ratio $1-2$. Seed reniform. Seeds mono-embryonic.

\section{Palmer}

Fruit length $11.5-15 \mathrm{~cm}$. Fruit diameter 7-9 cm. Fruit weight 500-700 gm. Fruit shape elliptical. Fruit apex obtuse. Fruit colour greenish red. Fruit stalk cavity absent. Fruit beak perceptible. Fruit sinus shallow. Fruit skin $2 \mathrm{~mm}$ thick or more. Colour of ripe fruit pulp orange. Texture of ripe fruit pulp firm. Fruit skin easily separable from pulp. Quantity of fibre in pulp low. Pulp of ripe fruit very juicy. Fibres adherent to skin of ripe fruit. Length of fibres in pulp less than $1.5 \mathrm{~cm}$. Pulp of ripe fruit aromatic. Pulp $75 \%$ or more. Stone length $9-12 \mathrm{~cm}$. Stone width $4.25-5 \mathrm{~cm}$. Stone length/width ratio 2 or more. Stone thickness less than $2 \mathrm{~cm}$. Stone weight $18-30 \mathrm{gm}$. Veins on stone superficial. Quantity of fibres on stone high. Fibres on stone less than $1.5 \mathrm{~cm}$ long. Fibres on stone soft. Seed length $4-6 \mathrm{~cm}$. Seed width $3-3.5 \mathrm{~cm}$. Seed length/width ratio $1-2$. Seed reniform. Seeds mono-embryonic.

\section{Qalb al-thoor}

Fruit length $11.5-15 \mathrm{~cm}$. Fruit diameter $9.5-11 \mathrm{~cm}$. Fruit weight $500-700 \mathrm{gm}$. Fruit shape oblong. Fruit apex obtuse. Fruit colour yellow with red blush. Fruit stalk cavity absent. Fruit beak mammiform. Fruit sinus absent. Fruit skin $2 \mathrm{~mm}$ thick or more. Colour of ripe fruit pulp yellow. Texture of ripe fruit pulp firm. Fruit skin strongly adherent to pulp. Quantity of fibre in pulp high. Pulp of ripe fruit juicy. Fibres adherent to skin of ripe fruit. Length of fibres in pulp about 1.5 $\mathrm{cm}$ or more. Pulp of ripe fruit aromatic. Pulp less than $75 \%$. Stone length 9-12 $\mathrm{cm}$. Stone width $4.25-5 \mathrm{~cm}$. Stone length/width ratio 2 or more. Stone thickness less than $2 \mathrm{~cm}$. Stone weight $30.1-44 \mathrm{gm}$. Veins on stone deep. Quantity of fibres on stone high. Fibres on stone less than $1.5 \mathrm{~cm}$ long. Fibres on stone coarse. Seed length $4-6 \mathrm{~cm}$. Seed width $3-3.5 \mathrm{~cm}$. Seed length/width ratio $1-2$. Seed oblong. Seeds poly-embryonic.

\section{Sensation}

Fruit length 9-11 cm. Fruit diameter 7-9 cm. Fruit weight 300-450 gm. Fruit shape oblong. Fruit apex obtuse. Fruit colour yellow with red blush. Fruit stalk cavity absent. Fruit beak prominent. Fruit sinus absent. Fruit skin $2 \mathrm{~mm}$ thick or more. Colour of ripe fruit pulp yellow. Texture of ripe fruit pulp firm. Fruit skin strongly adherent to pulp. Quantity of fibre in pulp high. Pulp of ripe fruit 
slightly juicy. Fibres adherent to skin of ripe fruit. Length of fibres in pulp about $1.5 \mathrm{~cm}$ or more. Pulp of ripe fruit aromatic. Pulp less than $75 \%$. Stone length 6-8.5 cm. Stone width 3-4 cm. Stone length/width ratio 2 or more. Stone thickness less than $2 \mathrm{~cm}$. Stone weight 18-30 gm. Veins on stone deep. Quantity of fibres on stone high. Fibres on stone less than $1.5 \mathrm{~cm}$ long. Fibres on stone soft. Seed length 4-6 cm. Seed width $3-3.5 \mathrm{~cm}$. Seed length/width ratio 1-2. Seed oblong. Seeds mono-embryonic.

Tommy Atkins

Fruit length $11.5-15 \mathrm{~cm}$. Fruit diameter 7-9 cm. Fruit weight $500-700 \mathrm{gm}$. Fruit shape ovoid. Fruit apex obtuse. Fruit colour yellow with red blush. Fruit stalk cavity present. Fruit beak mammiform. Fruit sinus absent. Fruit skin $2 \mathrm{~mm}$ thick or more. Colour of ripe fruit pulp yellow. Texture of ripe fruit pulp loose. Fruit skin strongly adherent to pulp. Quantity of fibre in pulp low. Pulp of ripe fruit juicy. Fibres adherent to skin of ripe fruit. Length of fibres in pulp less than $1.5 \mathrm{~cm}$. Pulp of ripe fruit aromatic. Pulp less than $75 \%$. Stone length 9-12 cm. Stone width $4.25-5 \mathrm{~cm}$. Stone length/width ratio 2 or more. Stone thickness less than $2 \mathrm{~cm}$. Stone weight $18-30 \mathrm{gm}$. Veins on stone deep. Quantity of fibres on stone high. Fibres on stone $1.5 \mathrm{~cm}$ long or more. Fibres on stone coarse. Seed length $6.5-8 \mathrm{~cm}$. Seed width $3-3.5 \mathrm{~cm}$. Seed length/width ratio $2.3-4$. Seed oblong. Seeds mono-embryonic.

\section{Van Dyke}

Fruit length 9-11 cm. Fruit diameter 7-9 cm. Fruit weight 300-450 gm. Fruit shape oblong. Fruit apex roundish. Fruit colour yellow with red blush. Fruit stalk cavity present. Fruit beak pointed. Fruit sinus shallow. Fruit skin $2 \mathrm{~mm}$ thick or more. Colour of ripe fruit pulp orange. Texture of ripe fruit pulp loose. Fruit skin easily separable from pulp. Quantity of fibre in pulp low. Pulp of ripe fruit juicy. Fibres not adherent to skin of ripe ruit. Length of fibres in pulp less than $1.5 \mathrm{~cm}$. Pulp of ripe fruit aromatic. Pulp less than $75 \%$. Stone length $6-8.5 \mathrm{~cm}$. Stone width $3-4 \mathrm{~cm}$. Stone length/width ratio 2 or more. Stone thickness less than $2 \mathrm{~cm}$. Stone weight $18-30 \mathrm{gm}$. Veins on stone deep. Quantity of fibres on stone high. Fibres on stone less than $1.5 \mathrm{~cm}$ long. Fibres on stone coarse. Seed length $4-6 \mathrm{~cm}$. Seed width $2-2.5 \mathrm{~cm}$. Seed length/width ratio $1-2$. Seed reniform. Seeds mono-embryonic.

Zill

Fruit length $9-11 \mathrm{~cm}$. Fruit diameter $9.5-11 \mathrm{~cm}$, or 7-9 cm. Fruit weight 500-700 gm. Fruit shape ovoid. Fruit apex acute. Fruit colour yellow with red blush. Fruit stalk cavity absent. Fruit beak pointed. Fruit sinus absent. Fruit skin $2 \mathrm{~mm}$ thick or more. Colour of ripe fruit pulp orange. Texture of ripe fruit pulp loose. Fruit skin easily separable from pulp. Quantity of fibre in pulp high. Pulp of ripe fruit very juicy. Fibres adherent to skin of ripe fruit. Length of fibres in pulp about $1.5 \mathrm{~cm}$ or more. Pulp of ripe fruit not aromatic. Pulp less than $75 \%$. Stone length $6-8.5 \mathrm{~cm}$. Stone width 3-4 cm. Stone length/width ratio 2 or more. Stone thickness less than $2 \mathrm{~cm}$. Stone weight $30.1-44 \mathrm{gm}$. Veins on stone deep. Quantity of fibres on stone high. Fibres on stone less than $1.5 \mathrm{~cm}$ long. Fibres on 
stone soft. Seed length $4-6 \mathrm{~cm}$. Seed width $3-3.5 \mathrm{~cm}$. Seed length/width ratio 1-2. Seed oblong. Seeds mono-embryonic.

\section{Items' descriptions}

For each cultivar the characters and character-states given in the detailed descriptions are replaced by the serial numbers assigned to them in Table 1; the numbers of a character and its state are separated by a comma.

\# \b\{\}Al-khad al-gameellb0 \{\}$/$

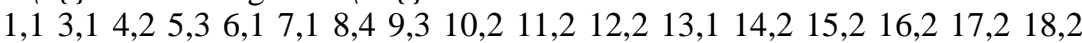

19,2 20,1 21,1 22,1 23,1 24,1 25,3 27,1 28,2 29,2 30,1 31,2 32,1 33,2 34,2

\# Fajrclan/

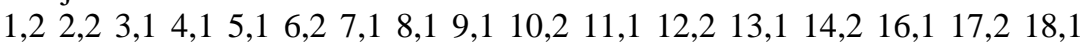

19,2 20,2 21,2 22,2 23,1 24,2 25,1 27,1 28,2 29,2 30,2 31,1 32,2 33,1 34,1

\# Hedan/

$\begin{array}{llllllllllllllllll}1,1 & 2,2 & 3,2 & 4,2 & 5,2 & 6,3 & 7,2 & 8,2 & 9,1 & 10,2 & 11,1 & 12,1 & 13,1 & 14,1 & 15,3 & 16,1 & 17,1\end{array}$

18,1 19,1 20,1 21,1 22,2 23,2 24,1 25,2 27,1 28,1 29,1 30,1 31,1 32,2 33,2 34,1

\# Keitt/

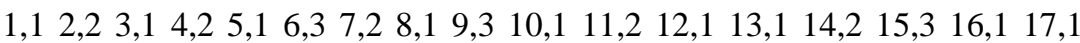

18,1 19,2 20,1 21,2 22,1 23,2 24,1 25,3 27,1 28,1 29,1 30,1 31,1 32,1 33,2 34,1

\# Kensington/

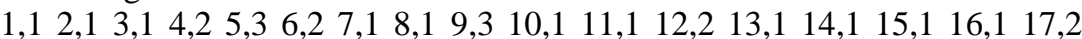

18,1 19,1 20,1 21,1 22,1 23,2 24,1 25,2 27,2 28,1 29,1 30,1 31,1 32,2 33,134,2

\# Kitchner (Sudani)/

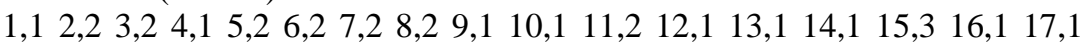

18,1 19,1 20,1 21,1 22,1 23,2 24,2 25,1 27,1 28,1 29,3 30,1 31,1 32,1 33,1 34,2 \# Nagwa/

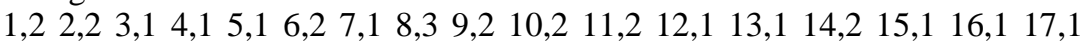

$18,219,2$ 20,2 21,1 22,2 23,1 24,1 25,3 27,2 28,2 29,1 30,1 31,1 32,2 33,134,2

\# Nielm/

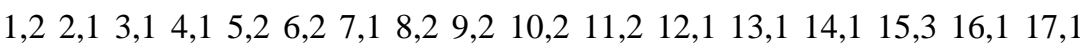

18,1 19,1 20,1 21,1 22,2 23,2 24,2 25,3 27,2 28,1 29,1 30,1 31,1 32,1 33,1 34,1 \# Palmer/

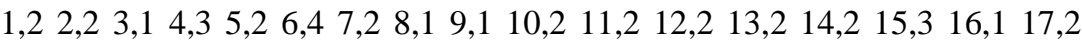

18,1 19,2 20,2 21,2 22,2 23,1 24,1 25,1 27,1 28,2 29,1 30,1 31,2 32,1 33,1 34,1 \# Qalb al-thoor/

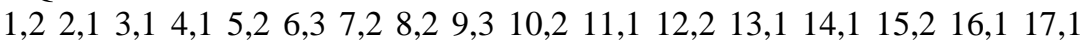

18,1 19,1 20,2 21,2 22,2 23,1 24,2 25,2 27,1 28,2 29,2 30,1 31,2 32,1 33,2 34,2 \# Sensation/

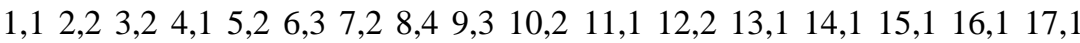

18,1 19,1 20,1 21,1 22,2 23,1 24,1 25,2 27,1 28,2 29,1 30,1 31,2 32,1 33,2 34,1 \# Tommy Atkins/

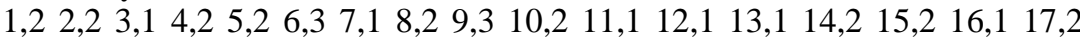

18,1 19,1 20,2 21,2 22,2 23,1 24,1 25,2 27,1 28,1 29,2 30,2 31,2 32,2 33,2 34,1 \# Van Dyke/

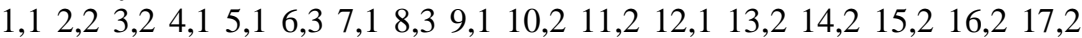

18,1 19,1 20,1 21,1 22,2 23,1 24,1 25,2 27,1 28,2 29,2 30,1 31,1 32,1 33,1 34,1

\# Zill/

Egypt. J. Bot., Vol. 56, No. 3 (2016) 


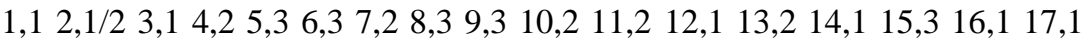
$18,219,120,121,122,2$ 23,1 24,2 25,2 27,1 28,2 29,1 30,1 31,2 32,1 33,2 34,1

\section{Discussion}

While recording the fruit and seed characters of the 14 mango cultivars in grown in Jazan, it was possible to distinguish between the cultivars with desirable and undesirable characters. Thus, cultivars "Al-khad al-gamil, Keitt, Qalb al-thoor, Sensation, Tommy Atkins and Zill" showed the commercial desirable characters such as bright color, aromatic juicy pulp and compressed thin stone which make it suitable for fresh consuming in domestic and exportation market. Some cultivars "Kensington, Hedan, Kitchner (sudani) and Nielm" (See Appendix) were characterized by some undesirable palatability characters which make them suitable for mango processing but not for fresh consumption. These characters are the loose pulp, low percentage of pulp, high quantity of fibers in the pulp, strong adherence of fruit skin to the pulp and thick stone with high quantity of long fibers. On the other hand, the remaining four cultivars "Fajrclan, Nagwa, Vandyke and Palmer" (See Appendix) were sharing some preferable fruit characters like the fibreless pulp and the low quantity of short fibers on stone which satisfy exportation market due to having good eating qualities, in addition these varieties represented good fruit storage characteristics, that kept fresh for ten days after harvesting. Since mangoes are denominated as climactic fruit and ripen quickly after harvest in addition to disease problems and general perishable nature of the fruit (Mitra and Baldwin, 2001), so good storage life is very important in a breeding programme. The perishable nature of mangoes and its short harvest season severely limit their use for fresh consumption and exportation (Marin et al., 1992).

The results proved that fruits of "Al-khad al-gamil" cultivar have the best desirable characters, like ovoid fruits which make it suitable for mechanical picking and packing systems as reported by Bally et al. (2009). The relatively large weighted fruits (500-700 gm) with average attractiveness; the firm, juicy pulp with low quantity of short fibers; there is no adherence of fibers to fruit skin; the percentage of pulp exceeds 75 ; stone is small weighted, thin and compressed with low quantity of short fibers; seeds are polyembryonic which make it suitable for different breeding programs.

Morphological and morphometric characters have the advantage of being simple to identify and do not need expert effort. Morphological characterization can be used as an important tool since published descriptors lists are readily available for most major crop species (Hoogendijk and Williams, 2001). Morphological and morphometric characterization criteria are thus important, that can be used as references in mango breeding programmes or in marketing.

The introduction of cultivars from one agroclimatic region to another has indicated that for certain characteristics some genotypes were stable while others were highly influenced by the environment (Iyer and Dinesh, 1997). Fruit length values for all cultivars in this study were different than stated in literature. There Egypt. J. Bot., Vol. 56, No. 3 (2016) 
were also cultivars in results for fruit skin colour of "Sensation" cultivar were found to be yellow with red blush which agreed with that reported by Campbell (1992) and Knight and Schnell (1994), but Mussane (2010) stated the fruit skin colour was green in color. Skin coloration of mature fruit in part results from anthocyanins that develop when tissues are exposed to light.

It is generally acknowledged that fruits for exportation should weigh approximately 500-700 gm and have good flesh quality. Therefore cultivars that can be selected for this purpose are "Al-khad al-gamil" and "Palmar" because they not only satisfy the weight requirement but also have a good flesh quality.

\section{Conclusion}

Correct identification of a commercial cultivar is undoubtedly the basic criterion for determining its market value and profitability which vary considerably from one cultivar to the next. The present study is the first attempt at solving the problems of accurate identification of mango cultivars in Jazan region, southwestern of Saudi Arabia. Unlike the currently prevailing method of identification of mango cultivars by visual observation of a few morphological characters of the fruit, the study succeeded in generating a conventional key based on 34 characters of the fruit and seeds recorded comparatively for the 14 cultivars grown in the region using the powerful set of computer programs DELTA. The results of using the key and the accompanying descriptions have the added advantage of being accurate and repeatable. Furthermore, it is noticeable in the prelude to the key that of the 34 characters included in the data matrix, only 12 were sufficient for generating the key, indicating the sound basis on which the key was built. The remaining characters in the detailed description of each species serve the all-important function of confirming the identifications achieved by using the key.

The data matrix incorporating the characters recorded for the 14 cultivars in Jazan region can be modified to cater for any alterations in their characters which might result from changes in the source trees of pollen grains. The data matrix is also sufficiently flexible to accommodate additional cultivars and their characters from all regions in the Kingdom as well as any other cultivars which might be introduced in the future.

It is recommended that future studies should include more cultivars from the collection at Saudi Arabia. Studies should also focus on morphological data, taking into account pest and disease resistance as well as genetic and cytological analysis. Future studies should also include genotype/environment interaction analysis over years. It is also recommended to introduce new cultivars from different countries in order to develop a better breeding programme.

Acknowledgments: The author thanks Jazan Agricultural Research Center at Abu Arish (southwestern of Saudi Arabia) for supplying specimens for the present study. 


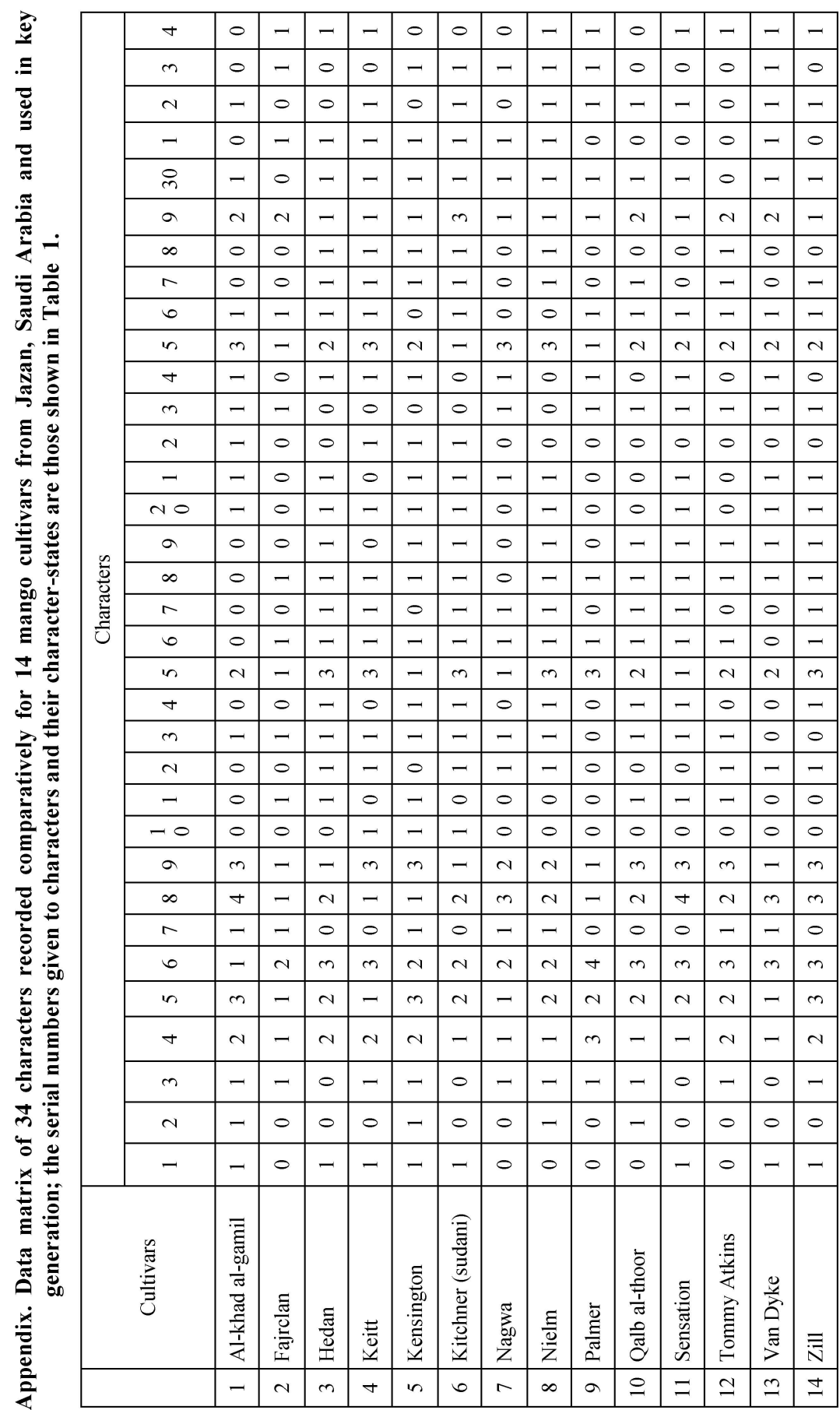

Egypt. J. Bot., Vol. 56, No. 3 (2016) 


\section{References}

Ascenso, J.C., Milheiro, A., Mota, M.I. and Cabral, M. (1981) Selecao preliminar da mangueira. Pesquisa Agropecuaria Brasileira, 16, 417-429

Bally, I.S.E, Lu, P. and Johnson, P.R (2009) "Breeding plantation Tree Crops". New York: Springer New York. pp. 53.

Campbell, R.J. (1992) "A Guide to Mango in Florida”. Miami: Fairchild Tropical Garden. de Azevedo, D.M.P.,

Crisostomo, J.R., Guedes, F.C.G. and Rosseti, A.G. (1998) Estimates of genetic correlations and correlated responses to selection in cashew (Anacardium occidentale L.). Genetics and Molecular Biology, 21, 3- 21.

Dallwitz, M.J., Paine, T.A. and Zurcher, E.J. (2000) "User's Guide to the DELTA System: A General System For Processing Taxonomic Descriptions". 4.12 ed. CSIRO Division of Entomology, Canberra, ACT, Australia. [also available at: http://deltaintkey.com].

Dawah, H.A., Alkahtani, S.A., Hobani, A.H. and Sahloli, S.N. (2013) The First Occurrence of Coptops aedificator (Fabricius) (Coleoptera: Cerambycidae) a pest of cultivated mango In South-Western Saudi Arabia, Journal of Jazan UniversityApplied Sciences Branch, 2 (2).

González, A., Coulson, M. and Brettell, R. (2002) Development of DNA markers (ISSRs) in Mango. Acta Horticulturae, 575, 139-143.

Griesbach, J. (2003) “Mango Book Kenia”. Nairobi, Kenia: World Agroforestry Centre.pp. 4-6.

Hoogendijk, M. and Williams, D. (2001) Characterizing the genetic diversity of home garden crops: Some examples from Americas. $2^{\text {nd }}$ International Home gardens workshop, 17-19 July 2001, Witzenhausen, Federal Republic of Germany. pp. 34-40.

Illoh, H.C. and Olorode, O. (1991) Numerical taxonomic studies of Nigerian mango varieties (Mangifera indica L.). Euphytica, 40, 197-205.

IPGRI, International Plant Genetic Resources Institute. (2006) Descriptors for mango. http//:www.bioversityInternational.org (Accessed 22/3/2007).

Iyer, C.P.A. and Dinesh, M.R. (1997) Advances in classical breeding and genetics in mango. Acta Horticulturae, 455, 252-267.

Jintanawong, S., Hiranpradit, H. and Chandraparnik, S. (1992) Quality standardization of Thai mango, Mangifera indica L. Acta Horticulturae, 321, 705-707.

Knight, R.J. and Schnell, R.J (1994) Mango introduction in Florida and the 'Haden' cultivar's significance to the modern industry. Economic Botany, 48, 139-145.

Marin, M.A., Cano, P. and Fuster, C. (1992) Freezing preservation of four Spanish mango cultivars (Mangifera indica L.): Chemical and biochemical aspects. Biomedical and Life Sciences, 194, 566-569. 
Mitra, S.K. and Baldwin, E.A. (2001) In: "Postharvest physiology and storage of tropical and subtropical fruits”. Mitra, S. (Ed). New York: CABI. pp. 85-111.

Mussane, CR. (2010) Morphological and genetic characterisation of mango (Mangifera indica L.) varieties in Mozambique, Master thesis, University of the Free State, Bloemfontein, South Africa.

Subedi, A., Bajracharva, J., Joshi, B.K., Gupta, S.R., Regmi, H.N., and Sthapit, B. (2009) Locating and managing the mango (Mangifera indica L.) genetic resources in Nepal. PGR-News, FAO-Biodiversity International, 115, 52-61.

(Received 18/1/2016; accepted 19/2/2016)

$$
\begin{aligned}
& \text { تعريف بعض أصناف المانجو في المملكة العربية السعودية } \\
& \text { باستخدام المفتاح الآلي واستخذامه كأداة للتقييم التجاري } \\
& \text { قديم العلوم البيولوجية والجيولوجية الغلية، كلية التربية، جامعة عين شمس، القاهرة، }
\end{aligned}
$$

تعتبر أشجار المانجو Mangifera indica واحدة من أهم الأشجار الاستوائية

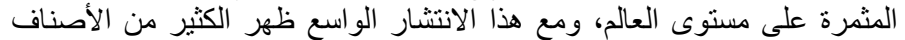

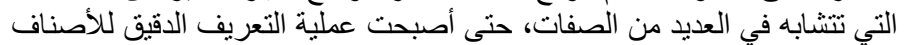

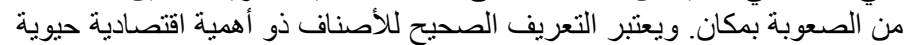

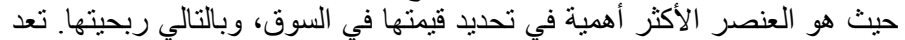

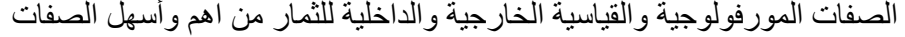

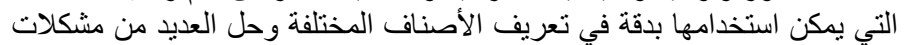

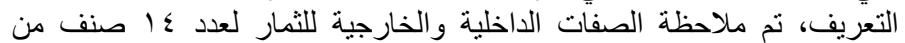

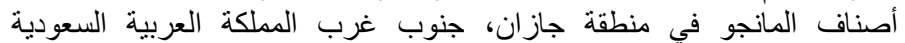

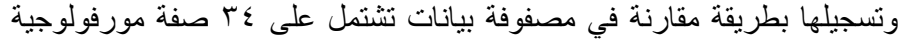

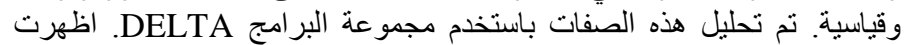

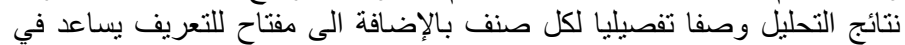

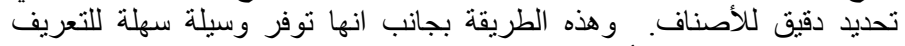

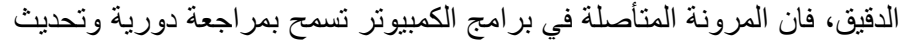

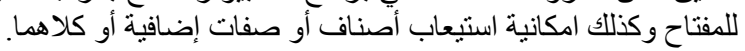

